\title{
Effects of socio-demographic characteristics and household water management on Aedes aegypti production in suburban and rural villages in Laos and Thailand
}

\author{
Nanthasane Vannavong ${ }^{1,2^{*}}$, Razak Seidu ${ }^{3}$, Thor-Axel Stenström ${ }^{4}$, Nsa Dada ${ }^{1}$ and Hans J Overgaard ${ }^{1,5}$
}

\begin{abstract}
Background: Dengue fever is a mosquito-borne disease accounting for 50-100 million annual cases globally. Laos and Thailand are countries in south-east Asia where the disease is endemic in both urban and rural areas. Household water storage containers, which are favourable breeding sites for dengue mosquitoes, are common in these areas, due to intermittent or limited access to water supply. This study assessed the effect of household water management and socio-demographic risk factors on Aedes aegypti infestation of water storage containers.

Methods: A cross-sectional survey of 239 households in Laos (124 suburban and 115 rural), and 248 households in Thailand (127 suburban and 121 rural) was conducted. Entomological surveys alongside semi-structured interviews and observations were conducted to obtain information on Ae. aegypti infestation, socio-demographic factors and water management. Zero-inflated negative binomial regression models were used to assess risk factors associated with Ae. aegypti pupal infestation.
\end{abstract}

Results: Household water management rather than socio-demographic factors were more likely to be associated with the infestation of water containers with Ae. aegypti pupae. Factors that was significantly associated with Ae. aegypti infestation were tanks, less frequent cleaning of containers, containers without lids, and containers located outdoors or in toilets/bathrooms.

Conclusions: Associations between Ae. aegypti pupae infestation, household water management, and socio-demographic factors were found, with risk factors for Ae. aegypti infestation being specific to each study setting. Most of the containers did not have lids, larvicides, such as temephos was seldom used, and containers were not cleaned regularly; factors are facilitating dengue vector proliferation. It is recommended that, in Lao villages, health messages should promote proper use and maintenance of tightly fitted lids, and temephos in tanks, which were the most infested containers. Recommendations for Thailand are that small water containers should be cleaned weekly. Furthermore, in addition to health messages on dengue control provided to communities, attention should be paid to larval control for indoor containers in rural villages. Temephos or other immature control measures such as the use of pyriproxyfen, antilarval bacteria, or larvivorous fish should be used where temephos resistance is prevalent. Dengue control is not possible without additional adult mosquito control and community participation.

Keywords: Aedes aegypti, Dengue, Laos, Thailand, Water storage

\footnotetext{
* Correspondence: anandafet@gmail.com

${ }^{1}$ Faculty of Science and Technology, Norwegian University of Life Sciences,

Ås, Norway

${ }^{2}$ Champasak Provincial Health Office, Pakse, Lao People's Democratic

Republic

Full list of author information is available at the end of the article
} 


\section{Background}

About 2.5 billion people are globally at risk of dengue, and 50-100 million cases of dengue fever are reported each year [1], but the number of cases is likely to be much higher [2]. The transmission of this mosquito-borne disease is considered urban, but it also occurs in rural areas [3-8]. The disease is caused by four serotypes of the dengue virus and is transmitted by two main mosquito species, Aedes aegypti and Ae. albopictus [9], which are both vectors of chikungunya and Zika viruses as well. The Lao People's Democratic Republic (hereafter Laos) and Thailand are dengue-endemic, and all four dengue serotypes have been reported in both countries [10, 11]. Based on the national dengue surveillance data from 2006-2012 in Laos [11], one outbreak in 2010 was recorded resulting in 46 deaths. Several outbreaks have been reported in Thailand during 2000-2011, with the largest in 2010 resulting in 139 deaths [12]. A three-fold increase in the morbidity rate occurred in Laos between 2009-2010 (from 119 to 367 cases/100,000 people) while the corresponding figures for Thailand was a two-fold increase (89-184 cases/100,000 people). In the south of Laos, dengue is the most common cause of non-malaria fevers [13, 14].

Because of water scarcity, poor infrastructure and intermittent operation of water supply, the storage of water at the household level is common in many parts of the developing world, including Laos and Thailand $[15,16]$. In both countries, water storage containers such as cement jars, tanks and others of various sizes have been used extensively for decades [17, 18]. Jars are normally used for storing drinking, and non-drinking water from rain and other sources piped to the house, while tanks are mostly used to store non-drinking water in toilets and bathrooms for bathing, laundry and cleaning [19]. However, as a result of improper household water management, these containers have become the preferred breeding sites for Ae. aegypti and an important risk factor for dengue fever transmission [17, 20-22].

Socio-demographic factors are known to affect dengue vector production and transmission. For instance, the risk of dengue in Thailand was associated with people gaining at least secondary education level and with households of more than four members [23]. Dengue modelling studies show that cases of dengue fever have a strong positive association with population density [24, 25]. Economic conditions were found to be associated with dengue cases, e.g. the seropositivity (immunoglobulin M, immunoglobulin G) of dengue was significantly associated with the absence of airconditioning in households [26]. However, these sociodemographic factors may vary depending upon setting and other complexities of the communities like socioeconomic dynamics, peoples' knowledge and behaviour, culture and geography.
Studies on dengue risk factors associated with household water storage, management and sociodemographic characteristics have rarely been conducted, particularly in Laos. According to a previous study conducted in southern Laos and north-eastern Thailand, high values of Stegomyia indices and Ae. aegypti production in water storage containers was identified [19]. Our study was conducted to identify the risk factors of household water management and socio-demographic characteristics on Ae. aegypti infestation in domestic water containers. Previously selected suburban and rural villages [19], one each in Laos and Thailand, were included in this study. Results from studies like this may provide important information for Ae. aegypti control programs to address the increasing threat of arboviral diseases, especially in light of the recent spread of Zika outbreaks.

\section{Methods \\ Study areas}

The study was conducted from the end of February to the beginning of June 2011, corresponding to the dry to the early wet season. One suburban and one rural village each in Thailand (Feb-April) and Laos (May-June) were surveyed. The selected villages in Laos were suburban Ban Lakhonesy $\left(15^{\circ} 53^{\prime} 29.18^{\prime \prime} \mathrm{N}, 105^{\circ} 33^{\prime} 56.59^{\prime \prime} \mathrm{E}\right)$ and rural Ban Okadnavien $\left(15^{\circ} 55^{\prime} 22.37^{\prime \prime} \mathrm{N}, 105^{\circ} 31^{\prime} 35.0^{\prime \prime} \mathrm{E}\right)$ in Salavan province, Southern Laos. In Thailand, the villages selected were suburban Ban $\operatorname{Han}\left(16^{\circ} 07^{\prime} 50.71^{\prime \prime} \mathrm{N}\right.$, $\left.102^{\circ} 32^{\prime} 5.81^{\prime \prime E}\right)$ and rural Ban Waileum (16 $10^{\prime} 48.95^{\prime \prime}$ N, $102^{\circ}$ 28'15.61"E), Khon Kaen province, northeastern Thailand (Fig. 1). The villages were selected based on previously described criteria [19].

\section{Study design}

A cross-sectional survey of 248 households in Thailand (127 suburban and 121 rural), and 239 in Laos (124 suburban and 115 rural) was conducted. Entomological surveys alongside semi-structured interviews and observations were conducted to obtain information on $A e$. aegypti infestation, socio-demographic factors and water management. In Thailand, the study sample represented 47 and $87 \%$ of all households in the selected suburban and rural villages, respectively. The corresponding numbers in Laos were $58 \%$ of the suburban households and $88 \%$ of the rural ones.

\section{Household socio-demographic characteristics}

Semi-structured interviews with the heads of each selected household (respondents) were conducted in the villages. Personal information of each respondent, such as age, sex, education level and occupation, were obtained. Education was categorised into two levels: primary school or less and more education than primary school. 


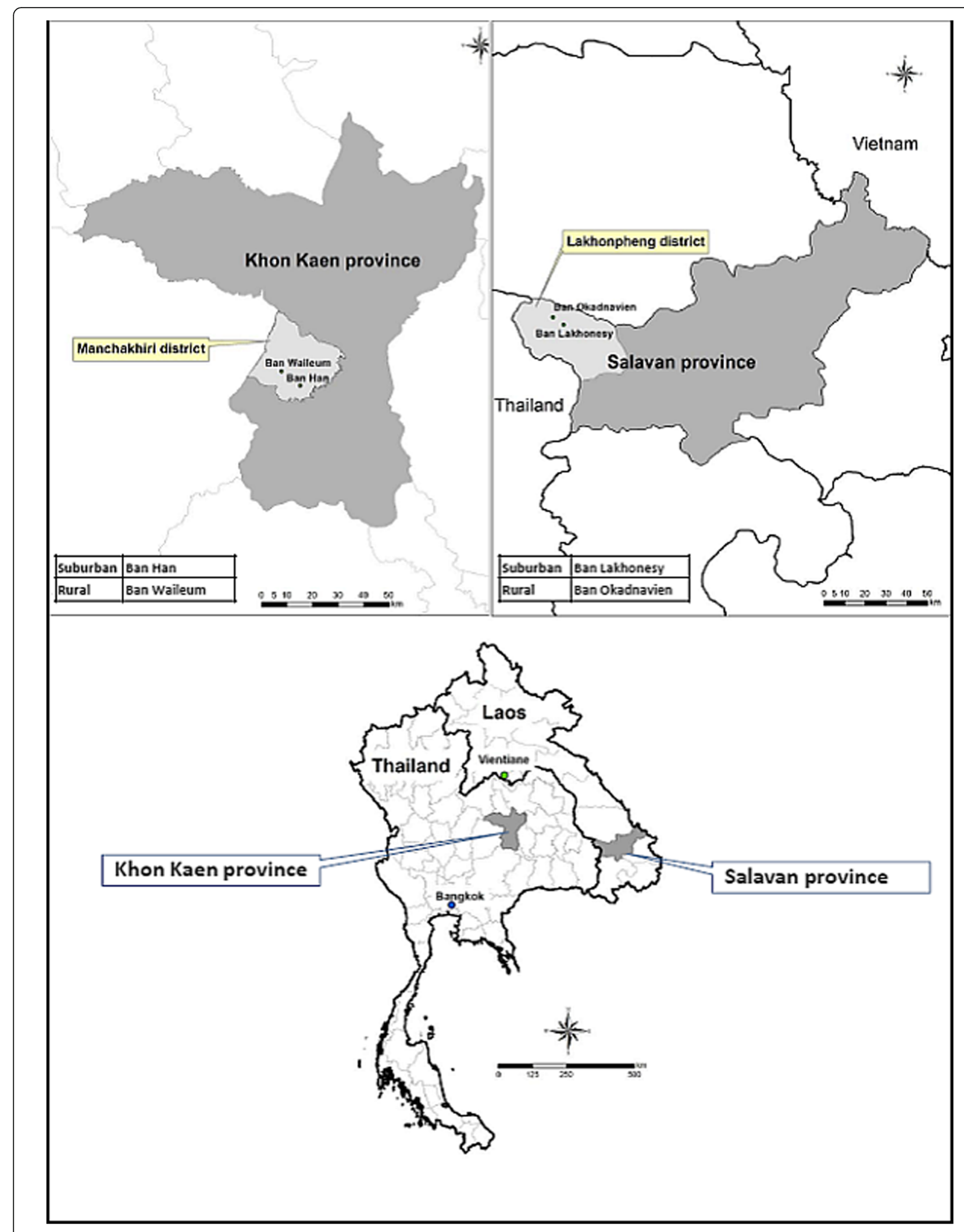

Fig. 1 Study villages in Laos and Thailand. Reprinted from Dada et al. (2013) Relationship between Aedes aegypti production and occurrence of Escherichia coli in domestic water storage containers in rural and sub-urban villages in Thailand and Laos. Acta Tropica, 126:177-185, with permission from Elsevier [19] 
Occupation was categorised into agriculture, commercial (e.g. shopkeepers and other business), service, and others (retired, unemployed or student). The main occupation of the people in all study villages was agriculture, especially rice farming although some people in Thailand, but not in Laos, also grow sugarcane and cassava. Information related to households' ownership of durable assets, habitable room occupancy and access to water was also collected. In addition to the semistructured interviews, observations were made of house material and recorded.

Household water management and entomological survey As part of the household water management survey, all water storage containers were classified according to type, presence or absence of a lid, the frequency of refill, and location. The sources of the household water were characterized as rain-fed (rainwater that is collected directly from the rooftop, through the roof connected tube or from a metal roofing sheet), manually collected rainwater (rainwater collected manually from larger containers), piped water into the household, or borehole water (i.e. boreholes or protected drilled wells owned by households and located in the housing areas). Containers were defined as being indoors if located under the main roof of the house or outdoors if located outside the house or under the eaves of the house. Containers in bathrooms/toilet were classified as a separate group (i.e. neither indoors nor outdoors). All household containers used for water storage were examined for mosquito pupae and larvae. If present, pupae were collected, counted, and brought back to the field station for identification using a dissecting microscope and illustrated keys as previously described [19]. All Aedes pupae were identified to Ae. aegypti and Ae. albopictus. Only thirteen pupae from the Lao study villages ( 5 suburban and 8 rural) were identified as Ae. albopictus. Therefore, this species was excluded in the analysis. A number of pupae were used as a dependent variable in the model of zero-inflated negative binomial regression (ZINB).

\section{Data analysis}

Descriptive analysis of socio-demographic and household water management characteristics was conducted for each study village. Further analysis was undertaken to derive additional risk factors such as room occupancy rate and wealth status of the households. Estimation of the room occupancy rate was based on United Nation's definition [27]. Wealth status of the households was ranked into rich, intermediate and poor using Principal Components Analysis (PCA) based on group weighted mean scores [28]. The variables used in the wealth status ranking are presented in Table 1.
Table 1 Variables used in the wealth status ranking

\begin{tabular}{ll}
\hline Variables & Options/Nalues \\
\hline House material & Cement/wooden/cement-wood \\
Room occupancy rate & Cement/wooden/cement-wood \\
& $\begin{array}{l}\text { >2.5 persons per habitable room/ } \\
\leq 2.5 \text { persons per habitable room }\end{array}$ \\
Ownership of durable assets & $\begin{array}{l}\text { Mobile phone/cell phone/TV/radio/ } \\
\text { refrigerator/car/motorcycle/bicycle }\end{array}$ \\
Affordability of bottled water & Can afford/cannot afford \\
Ownership of toilet facility & Yes/No \\
Ownership of flush toilet & Yes/No \\
Ownership of pour flush toilet & Yes/No \\
\hline
\end{tabular}

Univariate ZINB regression model was used to assess the independent effect of each of the socio-demographic and water management risk factors on the number of Ae. aegypti pupae in water containers. All factors included in the univariate analysis were then entered into a multivariate model to find the correlation between different factors and Ae. aegypti infestation in household storage water containers; and to eliminate confounding factors. The significant factors in the multivariate models were derived using backwards selection procedure. The unit of analysis with the ZINB model was the container. Statistical analyses were carried out using the statistical software SPSS 20.0 (IBM Corp.) and STATA (version 10; STATA Corporation, College Station, TX, USA). For the raw data used in the analyses please see Additional file 1.

\section{Results}

\section{General information of study villages}

The general description of the study villages is shown in Table 2 . In both rural villages, the majority of the respondents were farmers (94.8 in Laos and 95.9\% in Thailand). The level of education was low in both rural villages with 95.7 and $91.7 \%$ of the respondents having no more than primary education in Laos and Thailand, respectively. In both suburban villages, on the other hand, at least $47 \%$ of respondents had at least primary education. The room occupancy rate of $>2.5$ persons/ habitable room was lower in Thailand compared to Laos. In Thailand, 83 and $75 \%$ in the suburban and rural village respectively had a room occupancy rate of $\leq 2.5$ persons/habitable room. In Laos, this room occupancy rate was $50 \%$ in the suburban village and $63 \%$ in the rural village (Table 2). The socio-economic status (SES) was higher in Thailand compared to Laos with 60 and $31 \%$ of the households in suburban and rural Thailand falling under the rich category, respectively. 
Table 2 General information of respondents (household heads) and their households in a suburban and a rural village in Laos and Thailand (percentages in parentheses)

\begin{tabular}{|c|c|c|c|c|c|}
\hline & & \multicolumn{2}{|l|}{ Laos } & \multicolumn{2}{|l|}{ Thailand } \\
\hline & & Suburban & Rural & Suburban & Rural \\
\hline \multicolumn{2}{|l|}{ No. of households } & 124 & 115 & 127 & 121 \\
\hline \multirow[t]{2}{*}{ Gender } & Male & $40(32.3)$ & $48(41.7)$ & $66(51.9)$ & $88(72.7)$ \\
\hline & Female & $84(67.7)$ & $67(58.3)$ & $61(48.1)$ & $33(27.3)$ \\
\hline \multirow[t]{4}{*}{ Occupation } & Agriculture & $66(53.2)$ & 109 (94.8) & $30(23.6)$ & $116(95.9)$ \\
\hline & Commercial & $12(9.7)$ & $3(2.6)$ & $34(26.8)$ & $1(0.7)$ \\
\hline & Service & $30(24.2)$ & $3(2.6)$ & $11(8.7)$ & $2(1.7)$ \\
\hline & Other $^{a}$ & $16(12.9)$ & 0 & $52(40.9)$ & $2(1.7)$ \\
\hline \multirow[t]{2}{*}{ Education level } & $\leq$ Primary school & $58(46.8)$ & $110(95.7)$ & $77(60.6)$ & $112(92.6)$ \\
\hline & > Primary school & $66(53.2)$ & $5(4.3)$ & $50(39.4)$ & $9(7.4)$ \\
\hline \multirow[t]{2}{*}{ Room occupancy rate } & $>2.5$ persons/room & $62(50.0)$ & $43(37.4)$ & $22(17.3)$ & $30(24.8)$ \\
\hline & $\leq 2.5$ persons/room & $62(50.0)$ & $72(62.6)$ & $105(82.7)$ & $91(75.2)$ \\
\hline \multirow[t]{3}{*}{ Housing material } & Cement and wood & $48(38.7)$ & $16(13.9)$ & $88(69.3)$ & $74(61.2)$ \\
\hline & Cement & $25(20.2)$ & $1(0.9)$ & $27(21.3)$ & $15(12.4)$ \\
\hline & Wood & $51(41.1)$ & $98(85.2)$ & $12(9.4)$ & $32(26.4)$ \\
\hline \multirow[t]{4}{*}{ Floor material } & Cement and wood & $29(23.4)$ & $14(12.2)$ & $82(64.6)$ & $62(51.3)$ \\
\hline & Cement & $39(31.5)$ & $6(5.2)$ & $30(23.6)$ & $26(21.5)$ \\
\hline & Wood & $53(42.7)$ & $95(82.6)$ & $14(11.0)$ & $32(26.4)$ \\
\hline & Ground & $3(2.4)$ & 0 & $1(0.8)$ & $1(0.8)$ \\
\hline
\end{tabular}

${ }^{a}$ Retired, unemployed and student

Rural Laos had the highest proportion of poor households, $81 \%$ (Fig. 2).

Aedes aegypti pupae positive containers were found in all four study villages (Tables 3 and 4). In Thailand, 57 and $47 \%$ of the containers were positive for pupae in the suburban and rural village, respectively. In Laos, $54 \%$ in the suburban and 33\% in the rural village were pupae positive. The most important risk factors for
Ae. aegypti pupal presence and abundance were container type (jars and tanks), location (toilets/bathrooms), lid status (no lids), education level (primary level or less, except for suburban Laos), and SES (intermediate and rich households, except in rural Laos where $81 \%$ of the households were poor). However, some factors such as water source and container cleaning frequency were site specific.

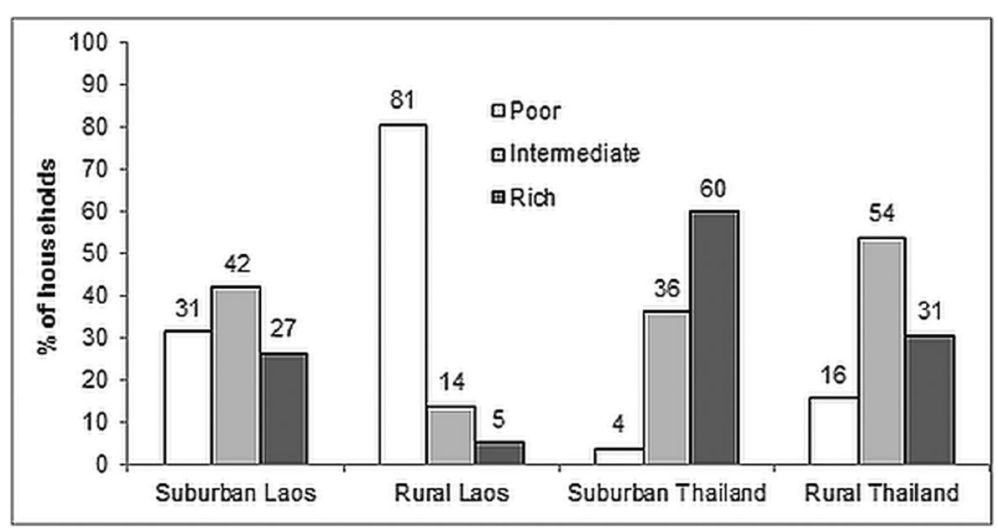

Fig. 2 The proportion of households classified as poor, intermediate, and rich in a suburban and a rural village in Laos and Thailand. Numbers above each bar represent the percentage of households within each location 


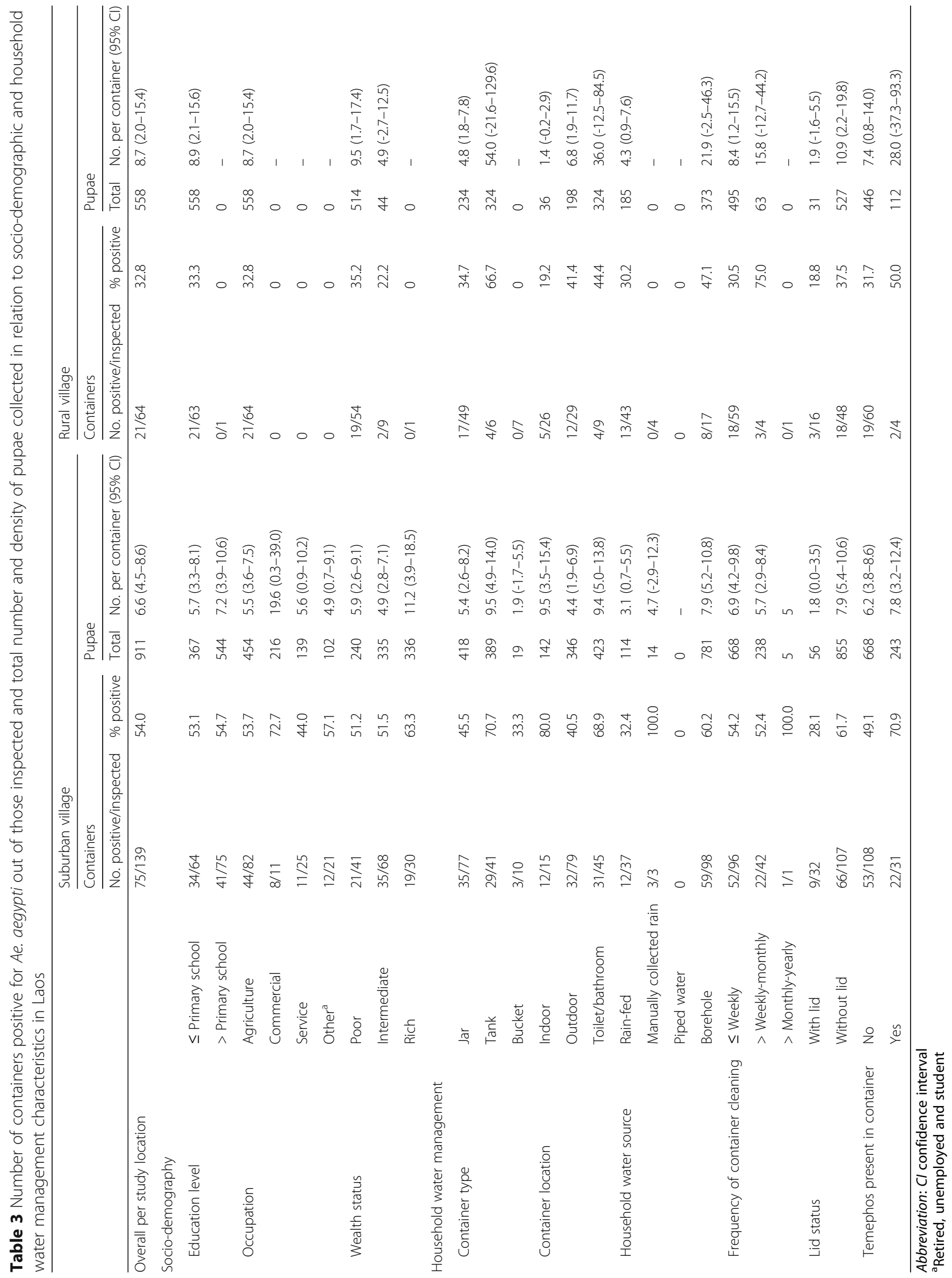




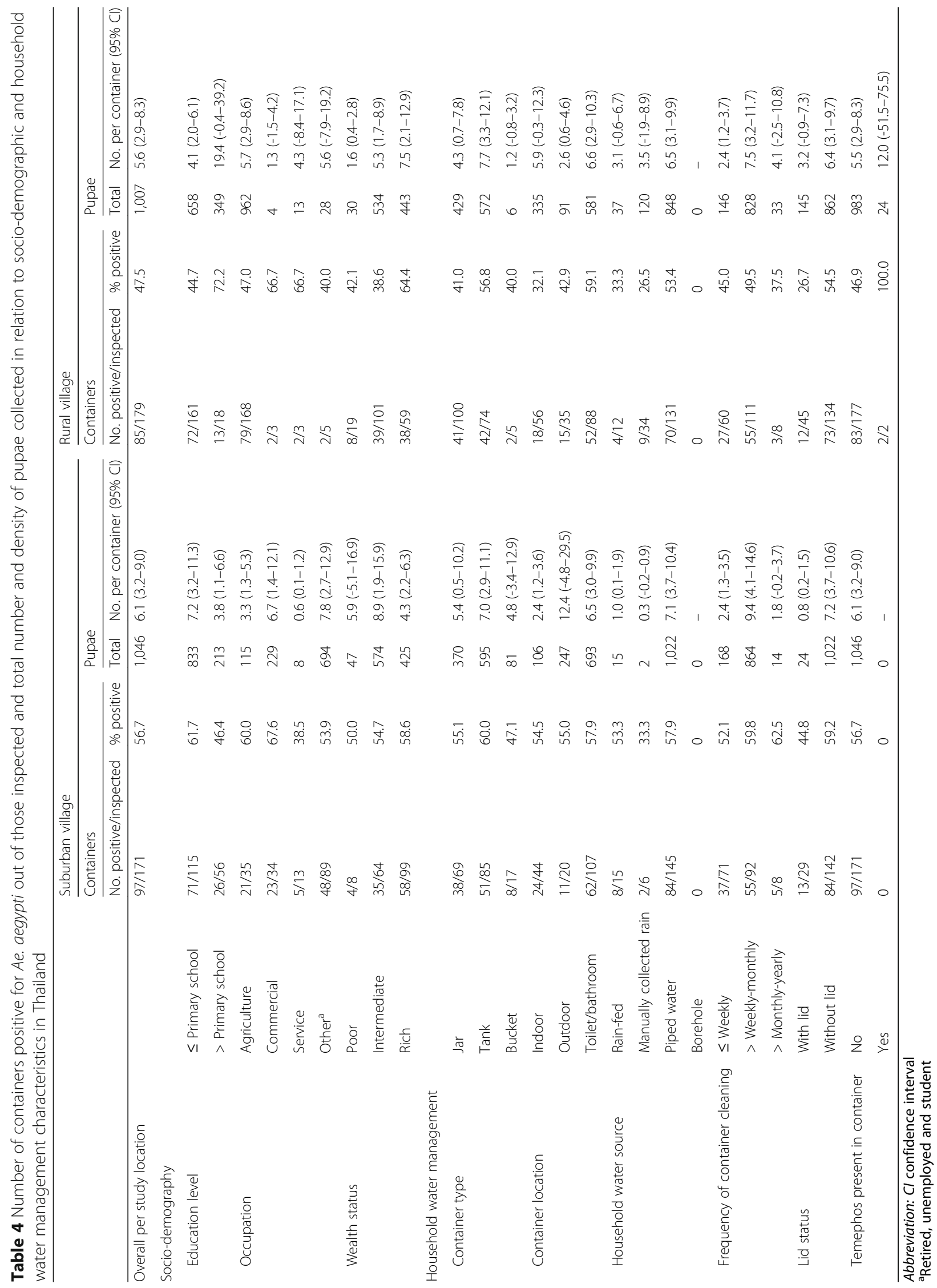




\section{Effect of socio-demographic characteristics on Aedes aegypti production}

The univariate analysis (Table 5) showed that households in suburban Laos where the respondent's occupation was 'commercial' were significantly associated with Ae. aegypti pupae abundance (IRR 2.9, 95\% CI: 1.01-8.8) compared to agricultural households. In suburban Thailand, respondents involved in 'other' occupations (retired, unemployed or student), were about three times more likely to have Ae. aegypti pupae in their homes, whereas, those who were services were less likely to have Ae. aegypti in their homes (IRR 0.2, 95\% CI: 0.1-0.8) compared to farmers' households. In the multivariate analysis, only 'other' occupations (IRR 2.3, 95\% CI: 1.1-4.8) in suburban Thailand remained significantly associated with Ae. aegypti (Table 6). In rural Thailand, 'commercial' occupations were less likely to have Ae. aegypti infestation in their homes (IRR 0.1, 95\% CI: 0.01-0.8) compared to those with agriculture occupation (Table 6). In rural Thailand, the houses of respondents who had a higher education than primary school were four times more likely to be infested with Ae. aegypti than in houses of respondents with lower education (Table 5). Households in rural Thailand assessed as being intermediate or rich were each about five times more likely to have their homes infested with Ae. aegypti compared to poor households (Table 5). In the multivariate model, these relationships became much stronger with households in the intermediate (IRR 9.3, 95\% CI: 3.1-28.1) and rich SES categories (IRR 13.2, 95\% CI: 4.01-43.3) being significantly associated with Ae. aegypti (Table 6).

\section{Effect of household water management on Aedes aegypti production \\ Container types and locations}

Jars and tanks were the most commonly used water storage containers across all four villages (Tables 3 and 4). The univariate model showed that container type was only significantly associated with Ae. aegypti pupae in rural Laos, and not in any other study village. Here, jars were the least likely to be infested (IRR 0.2, 95\% CI: 0.1-0.5) when compared to non-jar containers, and tanks were the most likely to be infested (IRR 6.3, 95\% CI: 2.0-19.9) when compared to non-tanks (Table 5). In the multivariate analysis, tanks remained the most likely to be infested (IRR 5.9, 95\% CI: 1.9-19.1), while jars were not significant (Table 6).

In Laos, $57 \%$ of water storage containers in the suburban village and $45 \%$ in the rural village were located outdoors. In Thailand, $63 \%$ of the containers in the suburban village and $49 \%$ in the rural village were found in toilets or bathrooms (Tables 3 and 4). For rural Laos, the univariate model showed that containers located in the toilet/bathroom were about 13 times more likely to be infested with Ae. aegypti pupae than those located indoors (Table 5). Container location was not of importance in suburban
Laos. In suburban Thailand, containers located in the toilet or bathroom (IRR 2.7, 95\% CI: 1.3-5.6) and those located outdoors (IRR 5.9, 95\% CI: 1.8-19.9) were more likely to be infested than indoor containers (Table 5). However, in rural Thailand, the opposite was observed; containers located outdoors were less likely to be infested compared to those located indoors (IRR 0.2, 95\% CI: 0.1-0.8) (Table 5). In the multivariate model for rural Thailand, containers located outdoors (IRR 0.2, 95\% CI: 0.1-0.5) and in the toilet/bathroom (IRR 0.4, 95\% CI: 0.2-0.9) were significant less likely to be associated with Ae aegypti pupae infestation (Table 6).

\section{Water sources}

In rural Laos, the univariate analysis showed that containers with water from boreholes and rainwater were significantly associated with Ae. aegypti. Containers with borehole water were 3.6 times (IRR 3.6, 95\% CI: $1.2-$ 11.1) more likely to be infested than containers with non-borehole water. Rain-fed water was significantly less likely to be infested with Ae. aegypti pupae than containers with other water sources (IRR 0.3, 95\% CI: 0.1-0.9). Similar outcomes were obtained in suburban Thailand, with manually collected rainwater being less likely to be infested (IRR 0.1, 95\% CI: 0.01-0.5) when other water sources were used as a reference. None of the water sources recorded was significantly associated with Ae. aegypti pupae in suburban Laos and rural Thailand. The multivariate model did not show any significant associations between water source and Ae. aegypti pupae across all four villages.

\section{Frequency of container cleaning, lid status and a presence of temephos in container}

In Laos, most of the containers in both rural (92\%) and suburban (69\%) villages were cleaned every week. The frequency of cleaning was not significantly associated with Ae. aegypti. In Thailand, the majority of the containers were cleaned less often than those in Laos. Fiftyfour percent and $62 \%$ of the containers in suburban and rural Thailand, respectively, were cleaned once during a period of a week and up to one month (Tables 3 and 4). As a result, these containers were more likely to be associated with Ae. aegypti in both the suburban (IRR 4.2, 95\% CI: 2.1-8.2) and the rural (IRR 3.5, 95\% CI: 1.6-7.4) villages (univariate model) compared to containers that were cleaned once a week (Table 5). This association remained significant in the multivariate model in the suburban (IRR 3.5, 95\% CI: 1.9-6.6) and the rural (IRR 2.6, 95\% CI: 1.3-5.1) village, respectively (Table 6).

In all study villages, most of the containers did not have lids. Only 23 and $25 \%$ of those in suburban and rural Laos, and 17 and $25 \%$ in suburban and rural Thailand, respectively were covered. Containers with lids 
Table 5 Incidence rate ratios, IRR (95\% confidence intervals) by univariate analysis of Ae. aegypti pupae per container in relation to socio-demographic and household water management in a suburban and a rural village in Laos and Thailand

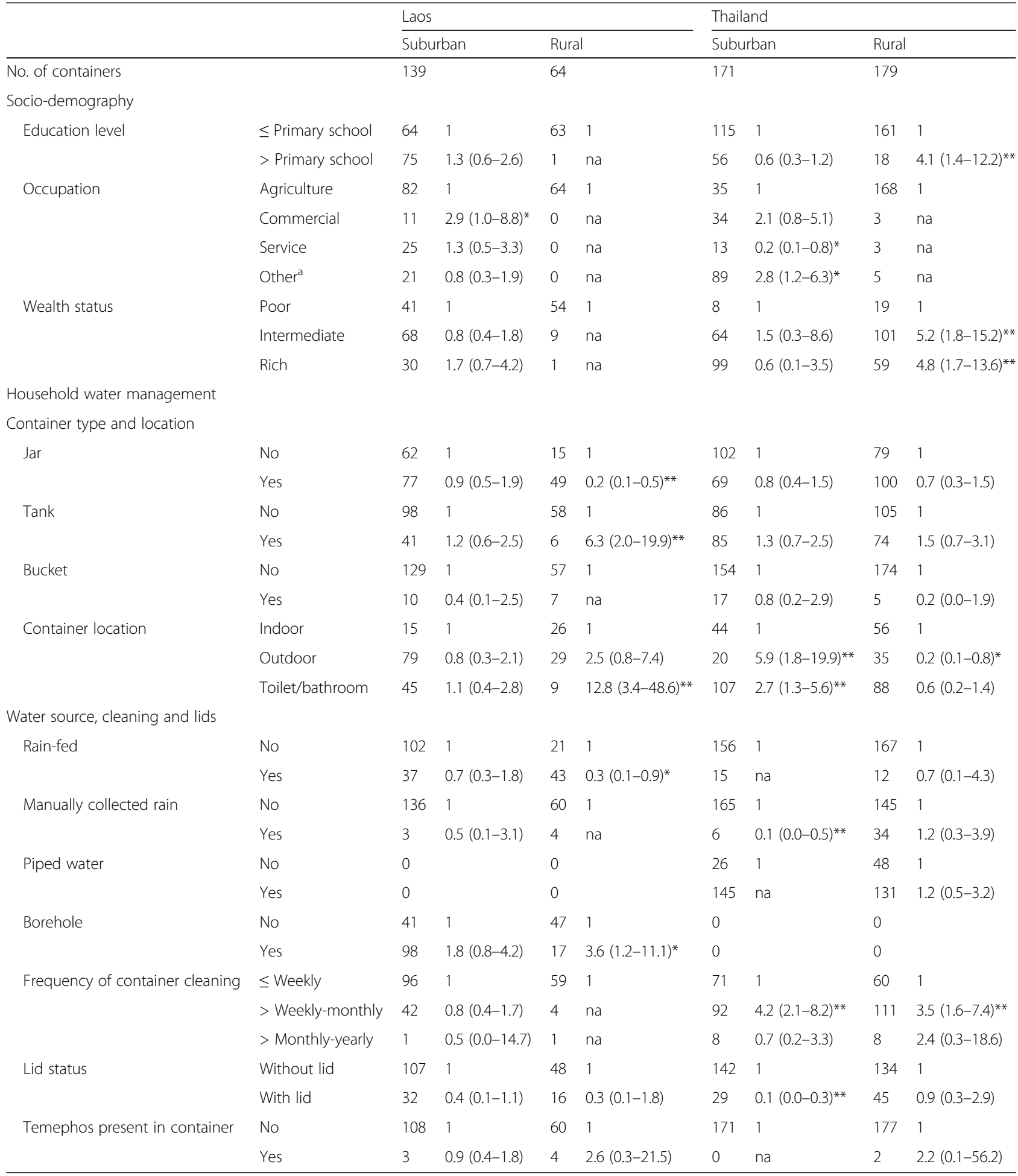


Table 6 Incidence rate ratios, IRR (95\% confidence intervals) by multivariate analysis of Ae. aegypti pupae per container in relation to socio-demographic and household water management in a suburban and a rural village in Laos and Thailand

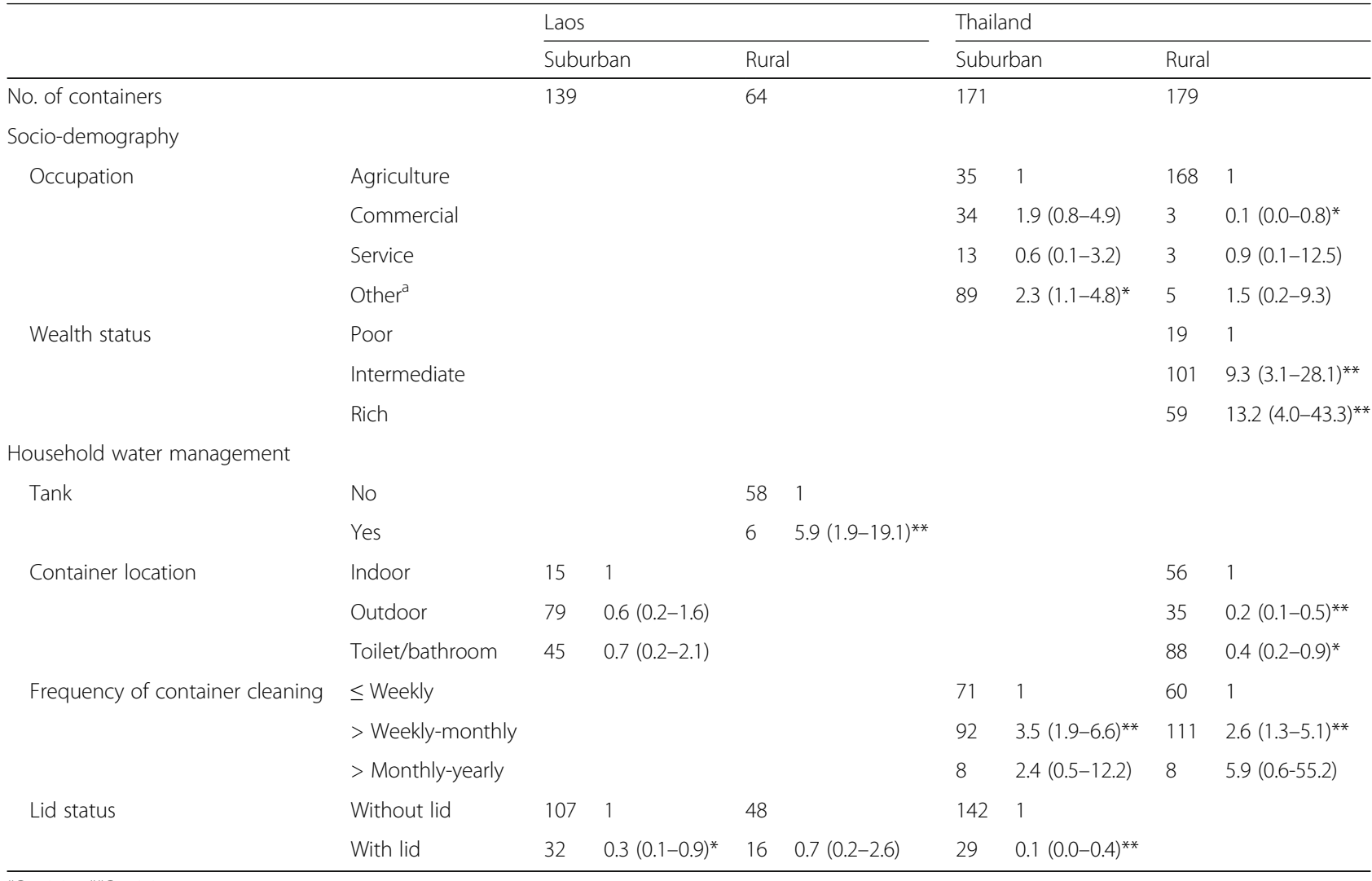

${ }^{*} P \leq 0.05,{ }^{* *} P \leq 0.01$

${ }^{a}$ Retired, unemployed and student

were significantly less likely to be infested than those without lids in the suburban villages in Laos (IRR 0.3, 95\% CI: 0.1-0.9) and Thailand (IRR 0.1, 95\% CI: 0.040.4) (Table 6). None of these associations was significant in the rural villages in either country (Tables 5 and 6).

In Laos, $22 \%$ of water storage containers in the suburban village and $6 \%$ in the rural village used the larvicide temephos (Abate). In Thailand, only one percent of containers in the rural village had temephos (Tables 3 and 4). There were no significant associations between temephos and Ae. aegypti pupae in both the univariate and multivariate models (Tables 5 and 6).

\section{Discussion}

The relationships between mosquito breeding and socioeconomic and water management factors are complex as shown in the study. Several risk factors associated with Ae. aegypti pupae infestation were relatively site specific. In Thailand, both socio-demographic and water management factors were to different degrees related to immature Ae. aegypti production. Very few significant associations between immature Ae. aegypti production and sociodemographic and water management factors were found in suburban Laos. The rural village is excluded from comparisons since it was a homogenous poor loweducational agricultural community.

\section{Socio-demographic relationships}

Specifically, the occupation of the household head and household wealth status were significantly associated with Ae. aegypti infestation in Thailand. The significance of occupation varied and was site specific. In suburban Laos where the respondent's occupation was 'commercial', there were significant associations with Ae. aegypti pupae abundance (IRR 2.9, 95\% CI: $1.01-$ 8.8) compared to agricultural households (which was the reference). In suburban Thailand, significant associations were also found with Ae. aegypti infestation, but in households where the occupation of the household head was 'other' (retired, unemployed or student). Households with 'other' occupations are not economically active and were the largest group $(41 \%)$ in the suburban village. Another study also showed that noneconomically active people were about 1.6 times more likely to have their households present with Ae. aegypti [29]. Those with agricultural occupations had a lower likelihood in both suburban sites. 
With regards to household wealth status in the rural Thai village, the intermediate households were nine times, and the rich households 13 times, more likely to have their home water containers infested with Ae. aegypti compared to the poorer households (Table 6). This may be because the intermediate and rich households had more water containers than the poor ones, thereby providing more breeding sites for Ae aegypti. This contrasts a previous study in Colombian towns where water containers in rich households were less likely to be infested with Ae. aegypti immatures compared to poor households [30].

\section{Water management factors}

Cement tanks were significantly more likely to be infested with Ae. aegypti compared to other containers in Laos (Tables 5 and 6). In both the suburban and the rural villages, cement tanks without lids were used to store non-drinking water in the toilets or bathrooms. The major challenge for Ae. aegypti larval control in many countries in south-east Asia is that such tanks, which are difficult to cover, are more likely to be used on a large scale $[19,21,31]$. In addition, large containers are often difficult to clean more frequently to enable the interruption and prevention of mosquito life-cycle and mosquito production. Less frequent cleaning provides good breeding sites for dengue vector production [32-36]. It is thus not the container type as such that is a factor for consideration but rather the combination of container size, their placement, no or poorly fitted lids and low frequency of cleaning that is the combined determinant of Aedes infestation. This is further supported by the other types of containers, such as jars in Laos, which were significantly less likely to be infested with $A e$. aegypti, especially in the rural village (Table 5) possibly due to their predominant use for the storage of drinking water and hence better handling (e.g. use of lids) and hygiene. This finding was contrary to those made in other studies where jars were considered a high-risk factor for mosquito breeding in Laos [37] and in Thailand [22], but again the combined purpose and handling practices will play a major role.

In the suburban village in Thailand, containers located outdoors and in toilets or bathrooms were more likely to be infested with Ae. aegypti than those located indoors, but in the rural village, outdoor containers were less likely to be infested (Table 5). It is unclear why this is so, but this could be because indoor containers in the suburban households were better handled and more often had lids than in the rural households. Rural households may provide better access for mosquitoes to indoor containers, which would be located in dark spaces, not well protected with lids and potentially providing attractive breeding sites. Again it is not only partly attributed to handling practices but also the purpose of the containers (example for drinking where the handling care is higher), our data showed there were more drinking water containers located outdoors in rural than in suburban villages of Thailand. In the suburban village outdoor containers were less often used for drinking (i.e. poorer hygiene). Other studies have shown that containers located outdoors are the main dengue vector producers compared to those located indoors [32, 34, 35, 38]. However, in Vietnam, the majority of Ae. aegypti immatures was found in indoor containers rather than outdoor containers $[31,39]$. Our results show the complexity of Ae. aegypti breeding, as they breed in a wide range of household containers regardless of location, especially under similar environmental conditions.

The handling practices are further supported by the cleaning practises and container type. Containers in Thailand were less frequently cleaned than those in Laos, due to a higher frequency of large containers in Thailand (e.g. large cement jar containing up to 2,000 l of water). Containers cleaned on a weekly basis were less likely to be infested with Ae. aegypti. A weekly cleaning schedule is also recommended by many national public health authorities and by WHO [40, 41]. The effectiveness of frequent cleaning has also been confirmed by studies in northern Thailand [33] and in six other Asian countries [35].

This study also showed that containers with lids act as prevention against mosquito breeding. Containers with lids were significantly less likely to be infested with $A e$. aegypti compared to those without lids in Laos (Table 6). This has also been shown in many other studies where containers without lids or partly covered produced more Ae. aegypti than those with lids [16, 31, 37, 42]. Container lids are not an absolute barrier and must be tightly fitted to prevent gravid females to enter for oviposition [43, 44]. Such lids are a low-cost, effective and environmental friendly intervention for dengue vector control and have also been recommended by the WHO [40]. However, this intervention needs to be properly managed and maintained by communities.

In rural Laos, containers with borehole water were almost four times more likely to be infested with $A e$. aegypti pupae compared to containers with other water sources (Table 5). Many containers with borehole water $(53 \%)$ (data not presented in results) were located in toilets or bathrooms, and all of them were without lids, all conditions that provide good breeding sites for Ae. aegypti [21, 31]. Conversely, rain-fed water was less likely to be infested compared to other water sources (Table 5). This could be because as many as $75 \%$ (data not presented in results) of the rain-fed containers were covered with lids and used for drinking. However, in the multivariate analysis 
(Table 6), water sources were not significantly associated with Ae. aegypti infestation.

Laos and Thailand have similar dengue outbreak responses. The so-called Surveillance and Rapid Response Teams (SRRT) act rapidly, within $24 \mathrm{~h}$ when a dengue case is diagnosed by a physician, to implement vector control measures. Such measures usually consist of space spraying with thermal fog within a radius of $100 \mathrm{~m}$ from the affected house. In addition, the larvicide temephos (Abate ${ }^{\circ} 1 \%$ sand granules) is freely provided nationwide in both countries. A systematic literature review showed that temephos was effective against Ae. aegypti production in water storage containers [45]. In the present study, it was found that some water containers in both villages of Laos contained temephos, but was mainly absent in Thailand (Tables 3 and 4). Thus, temephos was inconsistently used and may not have been an effective dengue control intervention in these settings. This could be due to problems of distribution or perceptions of temephos as a harmful chemical as well as improper use, which has been described in a study conducted in northeastern Thailand [46]. The indiscriminate use of temephos can lead to temephos resistance as identified in some parts of Thailand $[47,48]$. Pyriproxyfen, spinosad, or antilarval bacteria (e.g. Bti) have been shown to be effective against Ae. aegypti [49] and could be used instead of temephos. Control measures such as the use of larvivorous fishes were not observed in the examined containers but were sometimes observed in containers in other households not included in the study. Personal protection using repellents to control adult mosquitoes was also observed, but not accounted for in this study. However, for any of these control measures to be effective against Ae. aegypti, the involvement of multi-sectoral stakeholders as well as active community participation is key [50].

This study was a cross-sectional survey carried out at the end of the dry and the beginning of the wet season. Risk factors related to household water management may vary between seasons, and between years. The number of rainwater storage containers in the wet season would be higher than observed in our study, providing more breeding sites. Also, our study might have influenced nearby households to take action to clean out positive mosquito containers in their homes and thus biasing the results.

\section{Conclusions}

This study showed a relationship between Ae. aegypti production in water storage containers and risk factors associated with socio-demography and households' water management practices. Most of the risk factors were specific to the study villages. Our study showed that household water management rather than socio-demographic factors were more likely to be associated with the infestation of water containers with Ae. aegypti. Most of the containers did not have lids, were not protected with larvicides and were not cleaned regularly, thereby providing breeding sites for dengue vectors. As the aforementioned risk factors were significantly associated with Ae. aegypti infestation, it is recommended that, in Lao villages, health messages should promote proper use and maintenance of tightly fitted lids, and temephos in tanks, which were the most infested containers. Recommendations for Thailand are that small water containers should be cleaned weekly. Furthermore, attention should be paid to larval control for indoor containers in a rural village in addition to health messages. Temephos, which is the first larval control method of choice today, can be used in areas without temephos resistance. Alternatively, pyriproxyfen, spinosad, antilarval bacteria (e.g. Bti) or larvivorous fish should be considered where temephos resistance is prevalent. However, adult mosquito control must also be considered in an integrated vector management strategy. Compliance is always an issue when it comes to mosquito control. Therefore, community participation will be key to the success of any selected control measure.

\section{Abbreviations}

IRR: Incidence rate ratios; PCA: Principal Components Analysis; SES: Socioeconomic status; SRRT: Surveillance and Rapid Response Teams; UN: United Nations; WHO: World Health Organization; ZINB: Zero-inflated negative binomial

\section{Acknowledgements}

We would like to thank the Research Council of Norway, Norwegian University of Life Sciences, Ås, Norway for financial support. We would also like to thank the Water and Environmental Engineering Group at the Norwegian University of Science and Technology (NTNU) for the office space and logistical support in writing this paper. Dr Sibounhom Archkhawongs from the Ministry of Health in Laos, Prof. Theeraphap Chareonviriyaphap from the Department of Entomology, Kasetsart University, Bangkok, Thailand and Dr Ram Rangsin from the Phramongkutklao College of Medicine, Bangkok, Thailand are acknowledged for facilitating the study and for providing relevant information. Sincerely thanks to local authorities, fieldworkers and volunteers in Laos and Thailand for all their help and assistance.

\section{Funding}

This project was funded by the Research Council of Norway (Project no. 191652) and through a PhD grant to Nanthasane Vannavong from the Department of Mathematical Sciences and Technology, Norwegian University of Life Sciences.

\section{Availability of data and materials}

The data supporting the conclusions of this article are included within the article. Raw data are provided in Additional file 1.

\section{Authors' contributions}

NV, HJO, TAS conceived and designed the study. NV conducted the field work, analysed the data and drafted the manuscript. RS contributed in the study design, supervised data and water sample collection and data analyses. ND conducted the entomological survey. All authors read and approved the final manuscript.

Competing interests

The authors declare that they have no competing interests.

Consent for publication

Not applicable. 


\section{Ethics approval and consent to participate}

The study was approved by the National Ethics Committee for Health Research (NECHR), Ministry of Health, Vientiane, Lao PDR (No. 03/NECHR) on 17 December 2010 and by the Ethical Committee of Phramongkutklao College of Medicine, Bangkok, Thailand (S033h/53) on 21 March 2011. Informed signed consent was obtained from the household head of all participating households.

\section{Publisher's Note}

Springer Nature remains neutral with regard to jurisdictional claims in published maps and institutional affiliations.

\section{Author details}

${ }^{1}$ Faculty of Science and Technology, Norwegian University of Life Sciences, Ås, Norway. ${ }^{2}$ Champasak Provincial Health Office, Pakse, Lao People's Democratic Republic. 'Water and Environmental Engineering Group, Department of Civil Engineering, Institute for Marine Operations and Civil Engineering, Norwegian University of Science and Technology, Ålesund, Norway. ${ }^{4}$ SARChl Chair, Institute for Water and Waste Water Technology, Durban University of Technology, Durban, South Africa. ${ }^{5}$ Institut de Recherche pour le Développement (IRD), Maladies Infectieuses et Vecteurs, Ecologie, Génétique, Evolution et Contrôle (IRD 224-CNRS 5290 UM1-UM2), Montpellier, Cedex 5, France.

\section{Received: 23 November 2016 Accepted: 24 March 2017} Published online: 04 April 2017

\section{References}

1. WHO. Dengue. 2014. http://www.wpro.who.int/mediacentre/factsheets/fs_ 09032012_Dengue/en/. Accessed 14 Nov 2016.

2. Bhatt $S$, Gething PW, Brady OJ, Messina JP, Farlow AW, Moyes CL, et al. The global distribution and burden of dengue. Nature. 2013;496(7446):504-7.

3. Chareonsook O, Foy HM, Teeraratkul A, Silarug N. Changing epidemiology of dengue hemorrhagic fever in Thailand. Epidemiol Infect. 1999;122(01):161-6.

4. Strickman D, Sithiprasasna R, Kittayapong P, Innis BL. Distribution of dengue and Japanese encephalitis among children in rural and suburban Thai villages. Am J Trop Med Hyg. 2000;63(1-2):27-35.

5. Kumar A, Sharma SK, Padbidri VS, Thakare JP, Jain DC, Datta KK. An outbreak of dengue fever in rural areas of northern India. J Commun Dis. 2001;33(4):274-81.

6. Vong S, Khieu V, Glass O, Ly S, Duong V, Huy R, et al. Dengue incidence in urban and rural Cambodia: results from population-based active fever surveillance, 2006-2008. PLoS Negl Trop Dis. 2010;4(11):e903.

7. Mayxay M, Cui W, Thammavong S, Khensakhou K, Vongxay V, Inthasoum L, et al. Dengue in peri-urban Pak-Ngum district, Vientiane capital of Laos: a community survey on knowledge, attitudes and practices. BMC Public Health. 2013;13(1):1.

8. Dubot-Pérès $A$, Vongphrachanh $P$, Denny J, Phetsouvanh $R$, Linthavong $S$, Sengkeopraseuth B, et al. An epidemic of dengue-1 in a remote village in rural Laos. PLoS Negl Trop Dis. 2013;7(8):e2360.

9. WHO. Zika Virus. 2016. http://www.who.int/mediacentre/factsheets/zika/en/. Accessed 6 Jan 2017

10. Nimmannitya S, Halstead SB, Cohen SN, Margiotta MR. Dengue and chikungunya virus infection in man in Thailand, 1962-1964. I. observations on hospitalized patients with hemorrhagic fever. Am J Trop Med Hyg. 1969; 18(6):954-71.

11. Khampapongpane B, Lewis HC, Ketmayoon P, Phonekeo D, Somoulay V, Khamsing A, et al. National dengue surveillance in the Lao People's Democratic Republic, 2006-2012: epidemiological and laboratory findings. West Pac Surveill Response J. 2014;5(1):7-13.

12. Limkittikul K, Brett J, L'Azou M. Epidemiological trends of dengue disease in Thailand (2000-2011): a systematic literature review. PLoS Negl Trop Dis. 2014:8(11):e3241.

13. Mayxay M, Castonguay-Vanier J, Chansamouth V, Dubot-Pérès A, Paris DH, Phetsouvanh $\mathrm{R}$, et al. Causes of non-malarial fever in Laos: a prospective study. Lancet Glob Health. 2013;1(1):e46-54.

14. Mayxay M, Sengvilaipaseuth $O$, Chanthongthip A, Dubot-Pérès A, Rolain JM, Parola P, et al. Causes of fever in rural Southern Laos. Am J Trop Med Hyg. 2015;93(3):517-20.

15. Sommerfeld J, Kroeger A. Eco-bio-social research on dengue in Asia: a multicountry study on ecosystem and community-based approaches for the control of dengue vectors in urban and peri-urban Asia. Pathog Glob Health. 2012;106(8):428-35.

16. Quintero J, Brochero H, Manrique-Saide P, Barrera-Pérez M, Basso C, Romero $\mathrm{S}$, et al. Ecological, biological and social dimensions of dengue vector breeding in five urban settings of Latin America: a multi-country study. BMC Infect Dis. 2014;14(1):1.

17. Tonn RJ, Sheppard PM, Macdonald WW, Bang YH. Replicate surveys of larval habitats of Aedes aegypti in relation to dengue haemorrhagic fever in Bangkok, Thailand. Bull World Health Organ. 1969;40(6):819-29.

18. Kittayapong P, Strickman D. Distribution of container-inhabiting Aedes larvae (Diptera: Culicidae) at a dengue focus in Thailand. J Med Entomol. 1993;30(3):601-6.

19. Dada N, Vannavong N, Seidu R, Lenhart A, Stenström TA, Chareonviriyaphap T, et al. Relationship between Aedes aegypti production and occurrence of Escherichia coli in domestic water storage containers in rural and sub-urban villages in Thailand and Laos. Acta Trop. 2013;126(3):177-85.

20. Swaddiwudhipong W, Chaovakiratipong C, Nguntra P, Koonchote S, Khumklam P, Lerdlukanavonge P. Effect of health education on community participation in control of dengue hemorrhagic fever in an urban area of Thailand. Southeast Asian J Trop Med Public Health. 1992;23(2):200-6.

21. Tsuda Y, Kobayashi J, Nambanya S, Miyagi I, Toma T, Phompida S, et al. An ecological survey of dengue vector mosquitos in central Lao PDR. Southeast Asian J Trop Med Public Health. 2002;33(1):63-7.

22. Chareonviriyaphap T, Akratanakul P, Nettanomsak S, Huntamai S. Larval habitats and distribution patterns of Aedes aegypti (Linnaeus) and Aedes albopictus (Skuse), in Thailand. Southeast Asian J Trop Med Public Health. 2003:34(3):529-35.

23. Koyadun S, Butraporn P, Kittayapong P. Ecologic and sociodemographic risk determinants for dengue transmission in urban areas in Thailand. Interdisc Perspect Infect Dis. 2012;2012:907494.

24. Seng, S. B, Chong, A. K, Moore, A. Geostatistical modelling, analysis and mapping of epidemiology of denque fever in Johor State, Malaysia. 2005. https://ourarchive.otago.ac.nz/handle/10523/763. Accessed 3 Dec 2016.

25. Khormi HM, Kumar L. Modeling dengue fever risk based on socioeconomic parameters, nationality and age groups: GIS and remote sensing based case study. Sci Total Environ. 2011;409(22):4713-9.

26. Reiter $P$, Lathrop $S$, Bunning $M$, Biggerstaff $B$, Singer $D$, Tiwari $T$, et al. Texas lifestyle limits transmission of dengue virus. Emerg Infect Dis. 2003;9(1):86-9.

27. United Nations Statistics Division - Housing. 2016. http://unstats.un.org/unsd/ demographic/sconcerns/housing/housingmethods.htm\#Ea. Accessed 6 Jan 2017.

28. Vyas S, Kumaranayake L. Constructing socio-economic status indices: how to use principal components analysis. Health Policy Plan. 2006;21(6):459-68.

29. Spiegel JM, Bonet M, Ibarra AM, Pagliccia N, Ouellette V, Yassi A. Social and environmental determinants of Aedes aegypti infestation in Central Havana: results of a case-control study nested in an integrated dengue surveillance programme in Cuba. Trop Med Int Health. 2007;12(4):503-10.

30. Quintero J, Carrasquilla G, Suárez R, González C, Olano VA. An ecosystemic approach to evaluating ecological, socioeconomic and group dynamics affecting the prevalence of Aedes aegypti in two Colombian towns. Cad Saude Publica. 2009;25:593-103.

31. Tsuzuki A, Huynh T, Tsunoda T, Luu L, Kawada H, Takagi M. Effect of existing practices on reducing Aedes aegypti pre-adults in key breeding containers in Ho Chi Minh City, Vietnam. Am J Trop Med Hyg. 2009;80(5):752-7.

32. Ferdousi F, Yoshimatsu S, Ma E, Sohel N, Wagatsuma Y. Identification of essential containers for Aedes larval breeding to control dengue in Dhaka, Bangladesh. Trop Med Health. 2015;43(4):253.

33. Phuanukoonnon S, Mueller I, Bryan JH. Effectiveness of denque control practices in household water containers in Northeast Thailand. Trop Med Int Health. 2005;10(8):755-63.

34. Maciel-de-Freitas R, Marques WA, Peres RC, Cunha SP, Lourenço-de-Oliveira R. Variation in Aedes aegypti (Diptera: Culicidae) container productivity in a slum and a suburban district of Rio de Janeiro during dry and wet seasons. Mem Inst Oswaldo Cruz. 2007;102(4):489-96

35. Arunachalam N, Tana S, Espino F, Kittayapong P, Abeyewickrem W, Wai KT, et al. Eco-bio-social determinants of dengue vector breeding: a multicountry study in urban and periurban Asia. Bull World Health Organ. 2010;88(3):173-84

36. Tsunoda T, Cuong TC, Dong TD, Yen NT, Le NH, Phong TV, et al. Winter refuge for Aedes aegypti and Ae. albopictus mosquitoes in Hanoi during Winter. PLoS One. 2014;9(4):e95606.

37. Hiscox A, Kaye A, Vongphayloth K, Banks I, Piffer M, Khammanithong P, et al. Risk factors for the presence of Aedes aegypti and Aedes albopictus in 
domestic water-holding containers in areas impacted by the Nam Theun 2 hydroelectric project, Laos. Am J Trop Med Hyg. 2013;88(6):1070-8.

38. Morrison AC, Gray K, Getis A, Astete H, Sihuincha M, Focks D, et al. Temporal and geographic patterns of Aedes aegypti (Diptera: Culicidae) production in Iquitos, Peru. J Med Entomol. 2004;41(6):1123-42.

39. WHO. Key breeding sites of dengue vectors in Hanoi, Vietnam, 1994-1997. http://www.who.int/iris/handle/10665/148670. Accessed 7 Nov 2015.

40. WHO. Dengue: guidelines for diagnosis, treatment, prevention and control. 2009. http://www.who.int/tdr/publications/documents/dengue-diagnosis. pdf?ua=1. Accessed 14 Nov 2016

41. WHO. Western Pacific Regional Action Plan for Dengue Prevention and Control. 2016. http://www.wpro.who.int/about/regional_committee/67/ documents/wpr_rc67_5_dengue.pdf. Accessed 14 Nov 2016.

42. Koenraadt CJ, Tuiten W, Sithiprasasna R, Kijchalao U, Jones JW, Scott TW. Dengue knowledge and practices and their impact on Aedes aegypti populations in Kamphaeng Phet, Thailand. Am J Trop Med Hyg. 2006;74(4):692-700.

43. Strickman D, Kittayapong P. Laboratory demonstration of oviposition by Aedes aegypti (Diptera: Culicidae) in covered water jars. J Med Entomol. 1993;30(5):947-9.

44. Hammond SN, Gordon AL, Lugo ED, Moreno G, Kuan GM, López MM, et al. Characterization of Aedes aegypti (Diptera: Culcidae) production sites in urban Nicaragua. J Med Entomol. 2007:44(5):851-60.

45. George L, Lenhart A, Toledo J, Lazaro A, Han WW, Velayudhan R, et al. Community-effectiveness of temephos for dengue vector control: a systematic literature review. PLoS Negl Trop Dis. 2015;9(9):e0004006.

46. Phuanukoonnon S, Bough M, Bryan JH. Household practices of temephos use for dengue larval control, Khon Kaen Province, North-east Thailand. Dengue Bull. 2006;30:251-9.

47. Ponlawat A, Scott JG, Harrington LC. Insecticide susceptibility of Aedes aegypti and Aedes albopictus across Thailand. J Med Entomol. 2005;42(5):821-5.

48. Poupardin R, Srisukontarat W, Yunta C, Ranson H. Identification of carboxylesterase genes implicated in temephos resistance in the dengue vector Aedes aegypti. PLoS Negl Trop Dis. 2014;8(3):e2743.

49. Marcombe S, Darriet F, Agnew P, Etienne M, Yp-Tcha MM, Yébakima A, et al. Field efficacy of new larvicide products for control of multi-resistant Aedes aegypti populations in Martinique (French West Indies). Am J Trop Med Hyg. 2011;84(1):118-26.

50. Heintze C, Garrido MV, Kroeger A. What do community-based dengue control programmes achieve? A systematic review of published evaluations. Trans R Soc Trop Med Hyg. 2007;101(4):317-25.

\section{Submit your next manuscript to BioMed Central and we will help you at every step:}

- We accept pre-submission inquiries

- Our selector tool helps you to find the most relevant journal

- We provide round the clock customer support

- Convenient online submission

- Thorough peer review

- Inclusion in PubMed and all major indexing services

- Maximum visibility for your research

Submit your manuscript at www.biomedcentral.com/submit 